\title{
A New Controller to Enhance PV System Performance Based on Neural Network
}

\author{
Roshdy Abdelrassoul, SM, IEEE, Yosra Ali and Mohamed Saad Zaghloul \\ Arab Academy for Science, Technology and Maritime Transport (AASTMT), Alexandria, Egypt \\ roshdy@ieee.org, yosra_alii@hotmail.com, \\ dr_mszaghloul@yahoo.com
}

\begin{abstract}
In recent years, a radical increase of photovoltaic (PV) power generators installation has taken place because of the increased efficiency of solar cells, the growth of manufacturing technology of solar panels, in addition to the government support policy. This paper shows the operation and modeling of photovoltaic systems, particularly designing neural controller to control the system. Neural controller is optimized using particle swarm optimization (PSO), which leads to getting the best performance of the designed PV system. By using neural network, the maximum overshoot and rise time obtained become $0.00001 \%$ and 0.1798 seconds, respectively. Also, this paper strikes a comparison between some kinds of controller for the PV system.
\end{abstract}

Keywords - Particle Swarm Optimization, neural network and photovoltaic.

\section{INTRODUCTION}

The study of renewable energy sources has been an inclusive concern to the world, and has drawn the attention of many institutions, like the European Commission and others. Renewable energy is a clean energy system that has no effect during or after generation on the environment and this has grabbed the attention of researchers to make continuous improvement in solar energy. Renewable energy is numerous, abundant, sustainable, and can be utilized from different origins such as wind, solar, tidal, hydro, geothermal and biomass.

Solar energy could be one of the important sources as substitution energy for the hereafter. There are two kinds of technology that has anticipated solar energy, solar thermal and solar PV. A PV cell (solar cell) transforms sunlight into electrical energy by the photovoltaic effect.

The solar PV system exhibits various advantages, such as, it needs little maintenance and produces no environmental pollution. PV module presents the fundamental power conversion unit of a PV generator system.

\section{LITERATURE REVIEW}

Many papers have presented different simulations of PV system. In [1], a procedure for the simulation of photovoltaic modules with MATLAB/Simulink is presented. One-diode equivalent circuit is employed in order to investigate I-V and P-V characteristics of solar module. The final model takes irradiation, operating temperature in Celsius and module voltage as input and gives the output current Ipv and output voltage $\mathrm{Vpv}$. Also, in [2], a one-diode equivalent circuit-based versatile simulation model in the form of the masked block PV module is proposed. By using the model, it is allowed to estimate the behavior of PV module with respect to changes in irradiance intensity, ambient temperature and parameters of the PV module. In another study [3], a fractional-order PID (FOPID) controller [4-6] is designed to control a DC-DC boost converter in a PV-system. In order to obtain the best system performance, parameters of the proposed controller are tuned by using Particle Swarm Optimization (PSO) algorithm. In another paper [7], the effect of uniform and non-uniform irradiance on a series of connected solar PV array is presented in detail under MATLAB-Simulink environment. The proposed simulation model helps the researchers to investigate the characteristics of a PV array under different irradiance and temperature conditions [7].

This paper is framed around three major parts. First, an overview of mathematical model of the PV system is summed up. Second, a neural controller is designed to enhance the performance of the system. Finally, in order to obtain the best system performance, neural network of the proposed controller is optimized using the PSO. The system response is tested under various solar irradiation and constant temperature. Percentage overshoot (Mp) and rise time $(\mathrm{Tr})$ are measured and compared with 
other papers. The comparison shows that the system with the neural controller performs better than other systems with different kinds of controller.

\section{MATHEMATICAL MODEL OF THE PV SYSTEM}

\section{Mathematical Model of PV Panel}

The first part of the system is the solar cell. Solar cells are in fact large area semiconductor diodes. Due to the photovoltaic effect, energy of light (energy of photons) is converted into electrical current. The equivalent circuit for the simplest solar cell consists of a diode and a current source connected in parallel, as shown in Figure 1 [8]. The source current is directly proportional to the solar radiation and diode represents the PN junction of a solar cell.

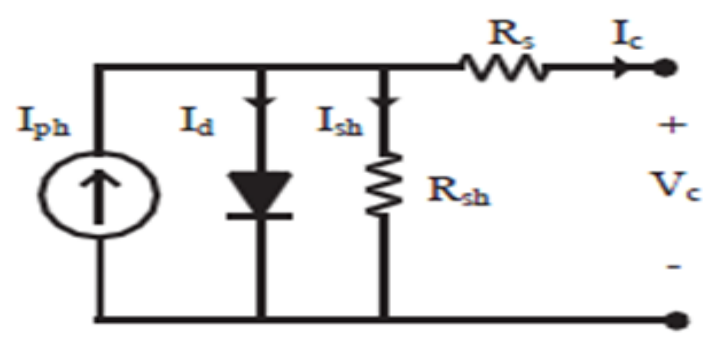

Fig.1. One diode model of PV cell
Equation of the load current is:

$I=\left[\left(I_{p h} \times N_{p}\right)-I_{d}-I_{s h}\right]$

\section{Where:}

$\left(\mathrm{I}_{\mathrm{ph}}\right)$ is photocurrent $(\mathrm{A})$;

$\left(I_{d}\right)$ is diode current;

$\left(I_{s h}\right)$ is the current loss because of the shunt resistance; and $(\mathrm{Np})$ the parallel connected PV cell number that effects the module current.

The thermal voltage equation is:

$V_{t}=\frac{k T}{q}$

Where:

(k) is boltzmann constant, $1.38 \times 10^{-23} \mathrm{~J} / \mathrm{K}$;

$(\mathrm{T})$ is solar cell temperature $(\mathrm{K})$; and

(q) is charge of electron, $1.6 \times 10^{-19} \mathrm{C}$.

The researchers represent the reverse saturation current equation for the proposed PV system using simulink on matlab as shwon in Figure. 2:

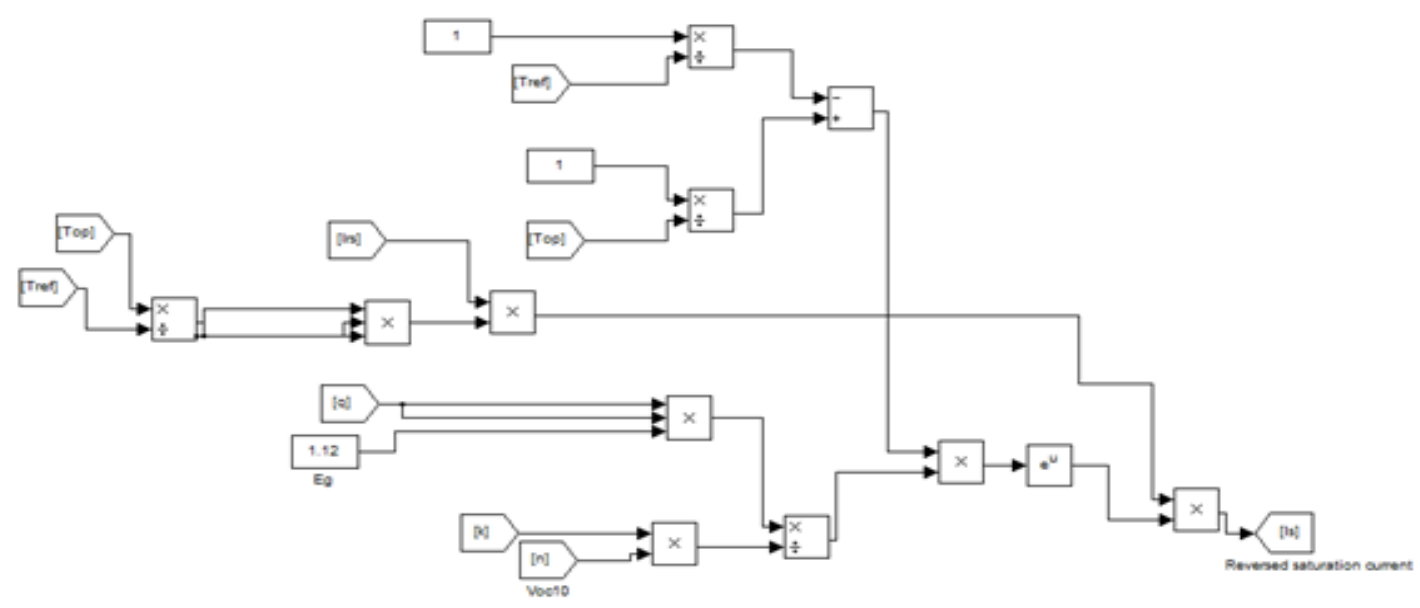

Fig.2. Reverse saturation current

$I_{S}=\left[\left(\frac{1}{T}-\frac{1}{T_{r e f}}\right) \times\left(\left(q^{2} \times E_{g}\right) /(k \times n)\right) e^{u}\left[\frac{I_{r s}}{\left(T^{T} / T_{r e f}\right)^{3}}\right]\right]$
The researchers represent the reverse saturation current at top equation for the proposed PV system using simulink on matlab as described in Figure. 3:

Where:

(T) the temperature of the PV panel;

( $\left.T_{\text {ref }}\right)$ the refrence temperature of the PV panel; 


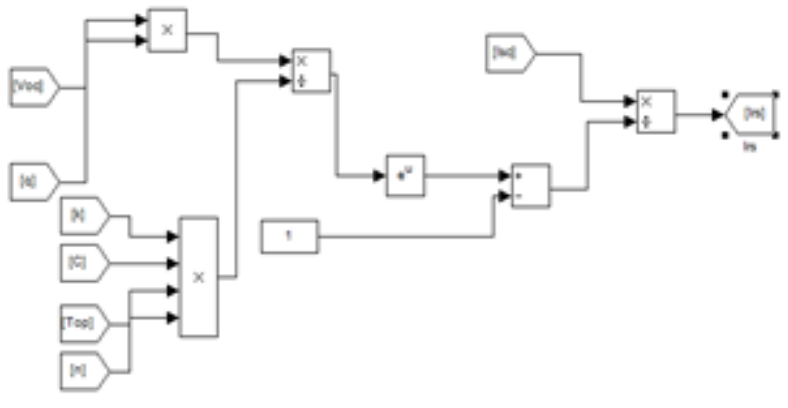

Fig. 3. Reverse saturation current at the top equation

$I_{r s}=\left[\left(V_{o c} * q\right) /(K * c * T * n)\right]\left[I_{s c} /\left(e^{u}-1\right)\right]$

where:

$\left(\mathrm{V}_{\mathrm{oc}}\right)$ open circuit voltag; and

$\left(I_{s c}\right)$ short circuit current.

Shunt current equation:

$I_{s h}=(V+I R) / R_{p}$

\section{Where:}

(Ish) shunt current;

$\left(R_{s}\right)$ the series resistance of the PV panel; and

$\left(R_{p}\right)$ the parallel resistance of the PV panel.

Diode current equation for the proposed PV system is described in Figure.4 as the researchers present it using Simulink on MATLAB:

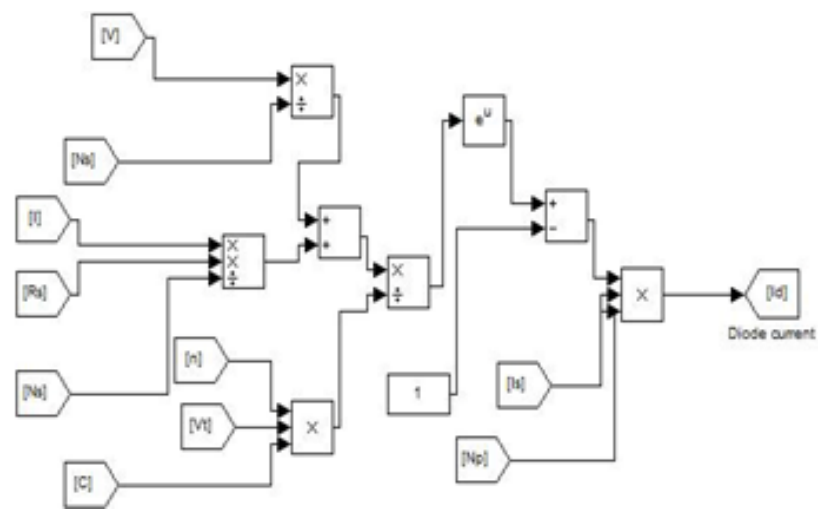

Fig. 4. Diode current

$I_{d}=\left[\left[\left(V / N_{s}\right)+\left(I * R_{s} / N_{s}\right)\right] /\left[n * V_{t} * c\right]\right]\left[\left(e^{u}-1\right) * I_{s} * N_{p}\right]$

Where:

(Id) diode current;

$\left(\mathrm{N}_{\mathrm{s}}\right)$ the series connected PV cell number that effects module voltage; and
$\left(\mathrm{V}_{\mathrm{t}}\right)$ thermal voltage;

phase current equation:

$I_{p h}=\left[\left(\left(T-T_{r e f}\right) * K\right)+I_{s c}\right] * I_{r r}$

Where:

(Irr) irradiation.

\section{Converter Model}

The second part of the system is the converter. A boost DC-DC converter is used as a power electronic interface between the load and PV panels in the P-V system. The converter is a powerful electronic device used to produce a higher regulated output voltage from a lower unregulated input voltage [3]. The circuit of the converter consists of an inductor $L$, a power switch S, a diode, D, a filter capacitor C and a load resistor $\mathrm{R}$, as shown in Figure 5 [3].

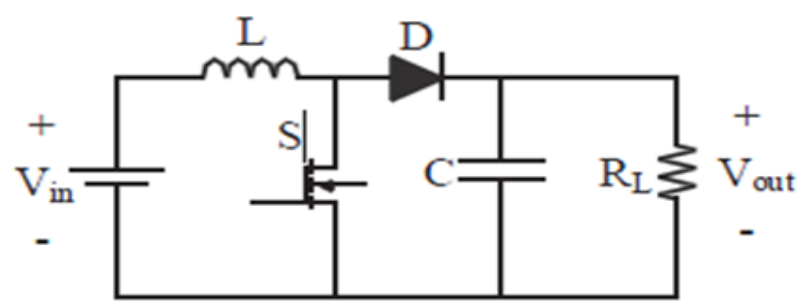

Fig. 5. Boost converter circuit

The working principle of the converter is cleared as follows: When the switch is in the ON mode, the diode is reverse biased (OFF). In this mode, the inductor is directly connected to the input voltage source and stores energy. Meanwhile, the load is powered by the capacitor. When the switch is OFF mode, the diode is forward biased (ON). In this mode, both the stored energy of the inductor and the input voltage source supply power to the load. The capacitor and the inductor values of the converter are calculated respectively by using the formulas [8]:

$C_{\text {min }}=\frac{D I_{\text {out }(\max )}}{f_{S} \Delta V_{\text {out }}}$

$L_{\text {min }}=\frac{\left(V_{\text {out }}-V_{\text {in }}\right) V_{\text {in }}}{\Delta I_{L} f_{S} V_{\text {out }}}$

Where:

$\left(\mathrm{C}_{\min }\right)$ and $\left(\mathrm{L}_{\mathrm{min}}\right)$ are the minimum capacitor and inductor values;

$\left(V_{\text {in }}\right)$ and $\left(V_{\text {out }}\right)$ are the input and output voltage of the 
converter;

$\left(f_{s}\right)$ is the switching frequency;

$\left(\Delta \mathrm{V}_{\text {out }}\right)$ is the output voltage ripple;

$(\Delta \mathrm{l} \mathrm{L})$ is the inductor current ripple; and

(D) is the duty cycle, which is the ratio between the pulse duration and period of a rectangular waveform.

\section{Neural Network Controller}

The third part in the system is the controller. There are numerous controllers that can be used to control dynamic systems like the PV systems. In this paper, neural network controller is used because neural networks are mostly used for fuzzy, difficult problems that do not yield to traditional algorithmic approaches. Many algorithms can be used to optimize the controller, such as Genetic algorithms (GA) [9], Differential Evolution (DE) algorithm [10] and PSO algorithm [11]. In this paper, Particle Swarm Optimization (PSO) will be used because it does not have genetic operators like crossover and mutation, since particles update themselves with the internal velocity. They also have memory, which is important to the algorithm, as will be explained later in the algorithm. Many papers used Proportional Integral Derivative controller (PID) instead of neural network. Neural network is more complex than PID controller but neural network gives a better response than the PID controller and some other kinds of controllers. In this paper, the neural network controller supported the designed model of the PV system.

A neural network is a method of computation modeled after the brain [12]. They contain a series of mathematical equations that are used to emulate biological processes such as learning and memory. What makes the artificial neural network unique from many other computer algorithms is its primitive ability to learn. Through a process of training and being told what the correct output is when given a set of inputs, the artificial neural network eventually learns the correct behavior, and can reproduce correct outputs on its own when given a set of inputs.

A neural network can predict an outcome based on the values of some predictor variables. Networks are programmed to adjust their internal weights based on the mathematical relationships identified between the inputs and outputs in a data set.

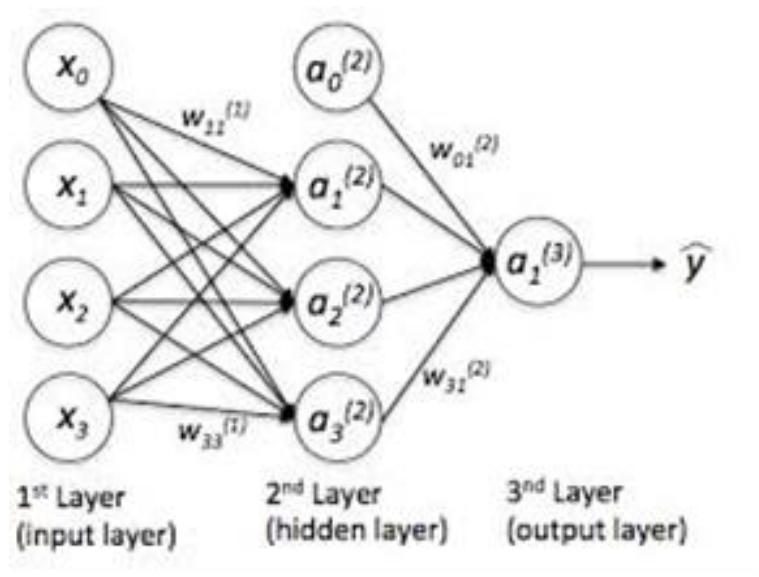

Fig. 6. Diagram of an artificial neural network

Table 1 is a brief glossary showing some common terms in the field of neural networks and their equivalent in statistics. Neural Networks are known to be universal function approximates. Various architectures are available to approximate any nonlinear function. Different architectures allow for generation of functions of different complexity and power. Those different architectures are:

- Feedforward networks

- Feedback networks

- Lateral networks

Table 1. Common Terms in Neural Networks and their Equivalent in Statistics

\begin{tabular}{|c|c|}
\hline Neural networks & Statistics \\
\hline Input & $\begin{array}{c}\text { Independent (predictor) } \\
\text { variable }\end{array}$ \\
\hline Output & $\begin{array}{c}\text { Dependent (outcome) } \\
\text { variable, predicted value }\end{array}$ \\
\hline Connection weights & Regression coefficients \\
\hline Bias weight & Intercept parameter \\
\hline Error & Residuals \\
\hline Learning, training & Parameter estimation \\
\hline Training case, pattern & Observation \\
\hline Cross-entropy & Maximum likelihood \\
\hline
\end{tabular}


In a neural network, the weights connecting two nodes are usually represented as where $\mathrm{i}$ and $\mathrm{j}$ are subscripts for the two nodes being connected. Estimating the optimal values of these connection weights is the major purpose behind training a neural network model. The network training algorithm is used to gradually adjust the weight and in the network to minimize the difference between the predicted output of the network $o_{p}$ and the known value of the outcome variable $t_{p}$. This difference is known as the error of a neural network and is similar to the concept of minimizing the residuals in statistical regression. The total error $(E)$ of a neural network is usually determined over the whole data set and may be calculated as shown in equation (10):

$E=\sum_{p}\left(t_{p}-o_{p}\right)^{2}$

Where $\mathrm{E}$ is the total error of the network $\mathrm{O}_{\mathrm{p}}$ and is the desired or known Neural Networks versus Logistic Regression.

\section{PARTICLE SWARM OPTAMIZATION (PSO)}

The Particle swarm optimization (PSO) method, suggested by Kennedy and Eberhart [13], is a computational search algorithm used to optimize a problem iteratively [14]. The algorithm is based on imitating the behaviors of a bird flock (particles) with the help of the mathematical velocity and position formulas of the particles. Each particle in the population has a memory to keep its previous best position called Pbest (candidate solutions, local minima) and fitness value. Also, the particle with minimum fitness value is called Gbest (global minima). The flowchart of the algorithm is given in Figure 7. Mathematical representations of the velocity and position of the particles are given below, respectively. Where $i$ is the number of the particle, $d$ is the dimension, $c_{1}$ and $c_{2}$ are the acceleration constant of the velocity, $w$ is the inertia weight, and $r_{1}$ and $r_{2}$ are the uniformly random numbers. Optimum values for these parameters are needed to reach robust transfer function for PV system. PSO is used widely in many applications due to its many advantages including its simplicity and easy implementation. PSO has no crossover and mutation process; however, the search can be done by the speed of the particle. Only the optimum particle can transmit information to the other particles, and the speed of searching is very fast. Thereby, the researchers used PSO as an optimization tool to find the optimum values for those parameters. The basic PSO algorithm consists of three steps generating positions of particles and velocities, velocity update, and position update. Each particle represents a possible solution to the problem that changes its position from one iteration to another based on velocity updates. First, the positions, xid, and velocities, vid, of the initial swarm of particles are randomly generated. The PSO consists of many particles which form a swarm, design space. At each step, each particle updates its velocity and distance according to Equation (8) and Equation (9), respectively.

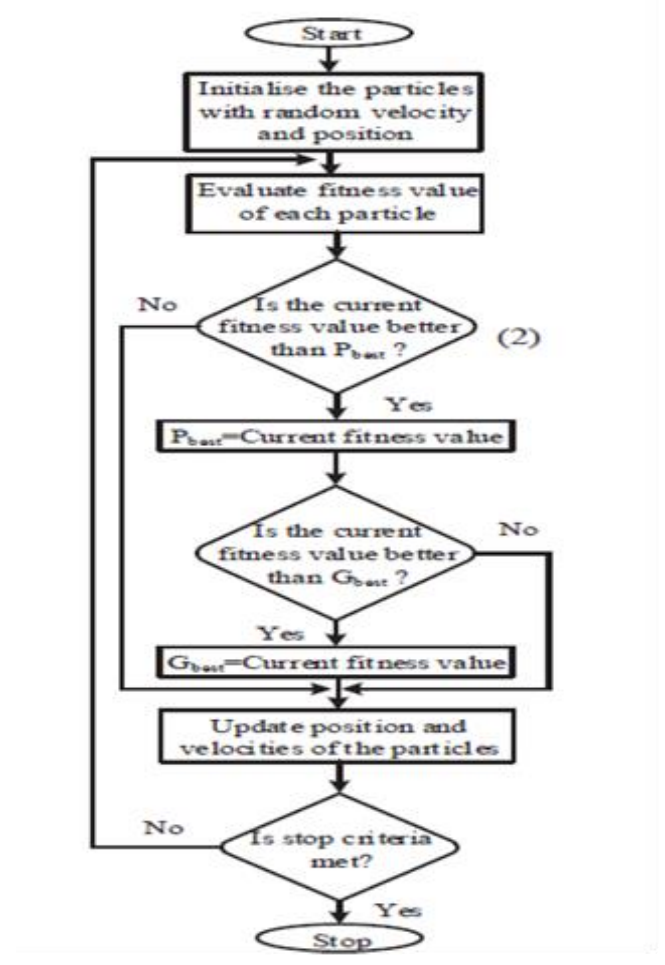

Fig. 7. A general flowchart of PSO

$V_{\text {id }}=w \times V_{i d}+c_{1} \times r_{1} \times\left(P_{i d}-X_{i d}\right)+c_{2} \times r_{2} \times\left(G_{i d}-X_{i d}\right)$

$X_{\mathrm{id}}=X_{i d}+V_{i a}$

The algorithm is ended when the stopping criteria are met.

\section{SIMULATION RESULTS}

According to the case study which is getting the best performance of a PV system by reducing rise time and the percentage overshoot, a neural controller is used as shown in Figure 8. Figures 9 and 10 represent the $\mathrm{I}-\mathrm{V}$ and $\mathrm{P}-\mathrm{V}$ characteristics of the system, respectively, with a solar irradiation input of $800 \mathrm{~W} / \mathrm{m}^{2}$. Table 2 shows the system parameters. 


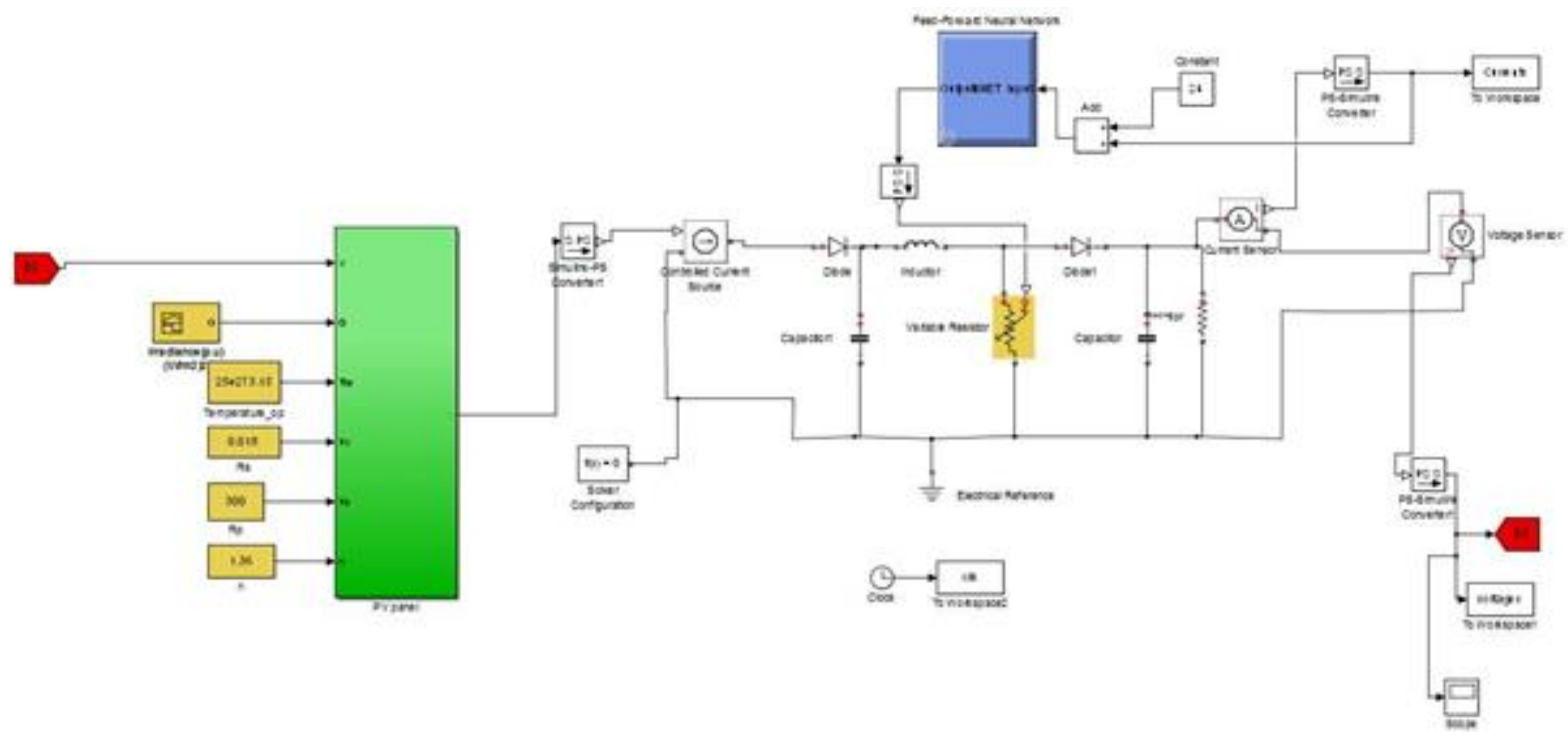

Fig. 8. Simulink/MATLAB architecture for the PV system with neural controller

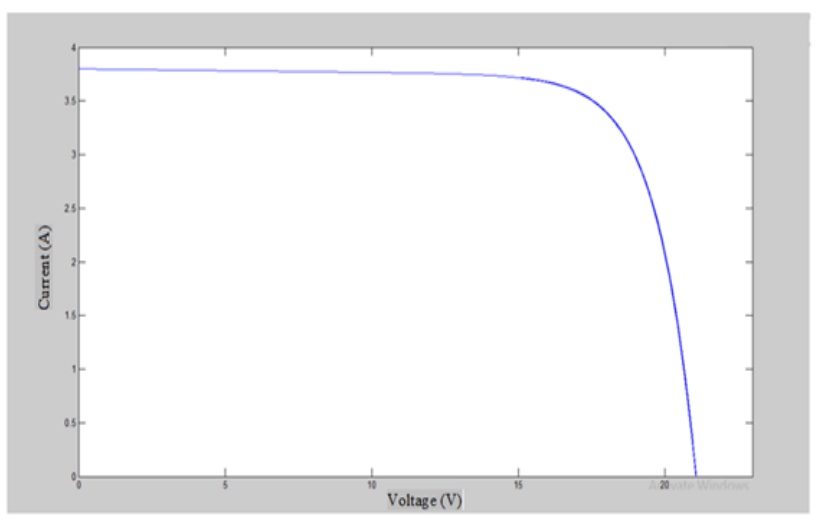

Fig. 9. Current - Voltage (I-V) characteristics of PV System

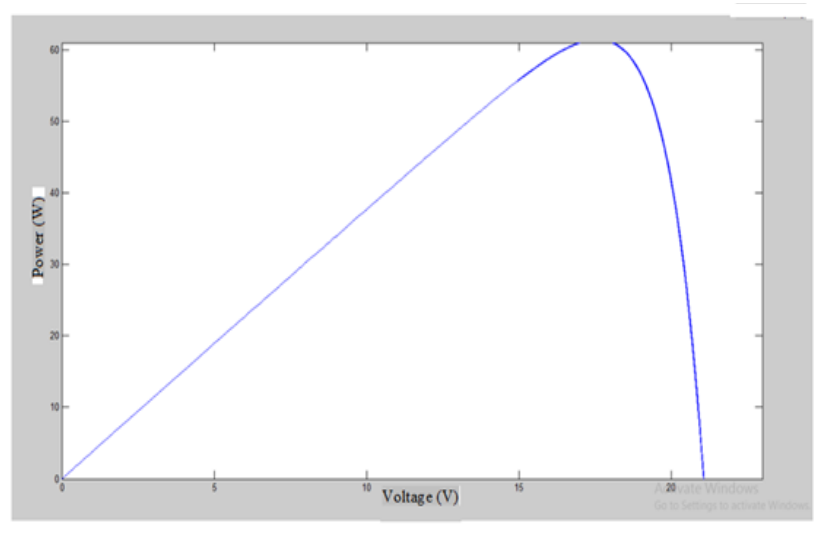

Fig. 10 Power- Voltage (P-V) characteristics of PV System
Table 2. Parameters of PV System

\begin{tabular}{|c|c|}
\hline Parameters of Boost Converter & \\
\hline Sampling frequency $\left(T_{s}\right)$ & $20 \mathrm{kHz}$ \\
\hline Switching frequency $\left(f_{s}\right)$ & $5 \mathrm{kHz}$ \\
\hline Output voltage $\left(\mathrm{V}_{\mathrm{O}}\right)$ & $24 \mathrm{~V}$ \\
\hline $\begin{array}{l}\text { Max. output voltage ripple } \\
(\Delta \mathrm{VC})\end{array}$ & $5 \%$ \\
\hline Max. input current ripple $(\Delta \mathrm{l})$ & $5 \%$ \\
\hline Input capacitor ( $\left.\mathrm{C}_{\mathrm{in}}\right)$ & $6.8 \mathrm{mF}$ \\
\hline Output capacitor ( $\mathrm{C}_{\text {out }}$ ) & $11.5 \mathrm{mF}$ \\
\hline Inductor (L) & $1.25 \mathrm{mH}$ \\
\hline Load (R) & 12.5-25-50Ohm \\
\hline \multicolumn{2}{|l|}{ PV panel parameters } \\
\hline $\mathrm{N}_{\mathrm{sc}}$ & 1 \\
\hline $\mathrm{N}_{\mathrm{pc}}$ & 5 \\
\hline $\mathrm{V}_{\mathrm{r}}$ & $17 \mathrm{~V}$ \\
\hline $\operatorname{lr}$ & $3 A$ \\
\hline$a$ & $3.10^{-3} \mathrm{~mA} /{ }^{\circ} \mathrm{C}$ \\
\hline$B$ & $-73.10^{-3} \mathrm{~mW} /{ }^{\circ} \mathrm{C}$ \\
\hline$I_{s c}$ & 3.5 \\
\hline $\mathrm{G}_{\mathrm{r}}$ & $1000 \mathrm{~W} / \mathrm{m}^{2}$ \\
\hline $\mathrm{T}_{\mathrm{cr}}$ & $25^{\circ} \mathrm{C}$ \\
\hline
\end{tabular}


There are a lot of types and training algorithms for neural network. In the proposed case, the researchers do not know which one will fit the best performance Therefore, they used the PSO to obtain the best neural type, training algorithm, number of hidden layers, and number of perceptions per layer. In this case, four parameters have to be determined. These parameters are shown in Table 3.

Table 3. Input Parameters of PSO

\begin{tabular}{|c|c|c|}
\hline Parameters & Description & Constrains \\
\hline$k 1$ & Neural type & From 1 to 4 \\
\hline$k 2$ & Training algorithm & From 1 to 12 \\
\hline$k 3$ & Number of layers & From 1 to 10 \\
\hline$k 4$ & Number of perception & From 1 to 10 \\
\hline
\end{tabular}

In equation 12, the $d$ represents the dimension number while the Pid represents the best previous position and the global best position is stored in $\mathrm{Pg}$. To ensure good coverage of the design space, the velocity update formula includes some random parameters, represented by the uniformly distributed variables, Rand. The three terms of the velocity update equations represent current motion, particle own memory, and swarm influence. Accordingly, the original PSO algorithm used the value of 2 for both constants $\mathrm{C} 1$ and $\mathrm{C} 2$. In the proposed problem, the objective function is minimizing the overshoot, rise time for the PV system. Also, the researchers used a swarm size of 49 in their proposed algorithm. In each iteration of PSO, the best parameters is stored as the global minimum. The parameters that should be optimized are summarized in Table 3. Once the PSO chooses the optimum parameter k1, k2, k3, and k4, those parameters are set as the final parameters for setup the neural network to operate as a controller instead of PID. Hence, the number of dimensions, $d$, in Equation 12 is equal to 12 . All the possible types and algorithms for $\mathrm{k} 1$ and $\mathrm{k} 2$ are mentioned in Table 4.
According to PSO, the optimum parameters are 2, 1 , 1 and 10 for $k 1, k 2, k 3$ and k4, respectively. This result reflects that the best type which fits the best performance for PV system is feed forward neural network with Levenberg-Marquardt training method, train Im. The upcoming Figure 11 will illustrate the overshoot $0.00001 \%$ and that rise time equals 0.170 seconds.

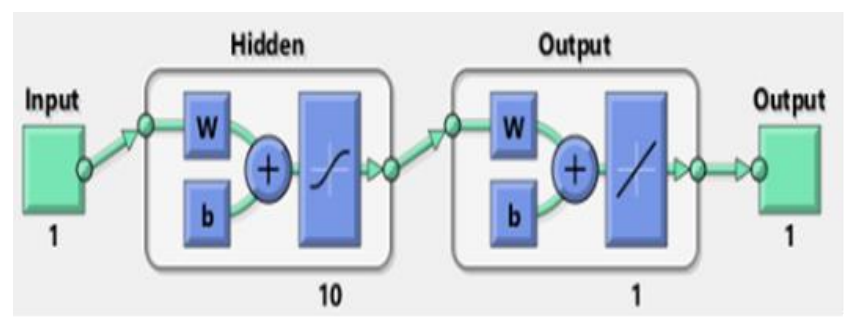

Fig. 11. Structure of the proposed neural network

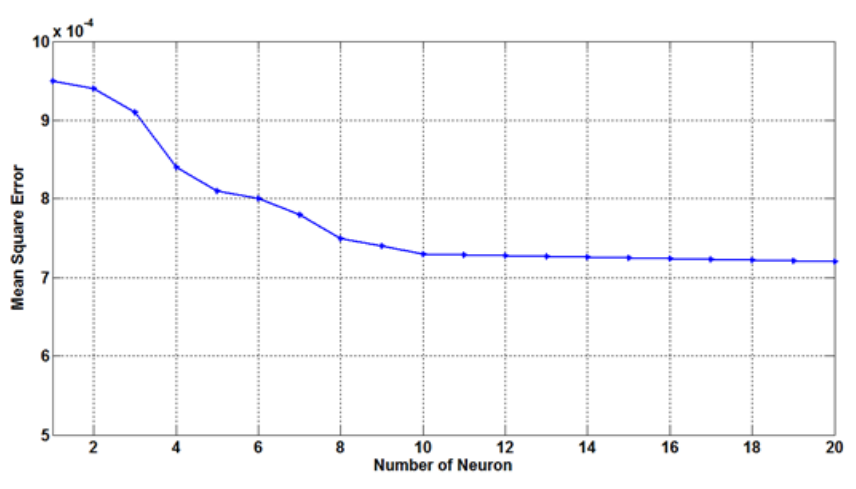

Fig. 12. The value of MSE

Step Response of Solar Cell System with Nueral Controller

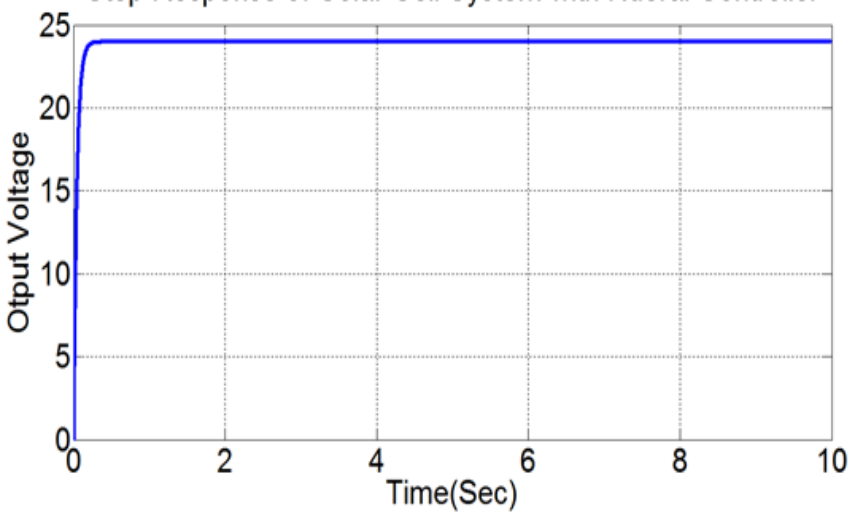

Fig. 13. Step response of process with neural controller unig Simulink 
Table 4. All Possible Values and Types for k1 and k2

\begin{tabular}{|c|c|c|}
\hline Parameters & Value & Type \\
\hline \multirow{4}{*}{ k1 } & 1 & Cascade forward net \\
\cline { 2 - 3 } & 2 & Feed forward net \\
\cline { 2 - 3 } & 3 & Pattern net \\
\cline { 2 - 3 } & 4 & Fit net \\
\hline \multirow{5}{*}{ k2 } & 1 & trainlm \\
\cline { 2 - 3 } & 2 & trainbr \\
\cline { 2 - 3 } & 3 & trainbfg \\
\cline { 2 - 3 } & 4 & trainrp \\
\cline { 2 - 3 } & 5 & trainscg \\
\cline { 2 - 3 } & 6 & traincgb \\
\cline { 2 - 3 } & 7 & traincgf \\
\cline { 2 - 3 } & 8 & traincgp \\
\cline { 2 - 3 } & 9 & trainoss \\
\cline { 2 - 3 } & 10 & traingdx \\
\cline { 2 - 3 } & 11 & traingdm \\
\cline { 2 - 3 } & 12 & traingd \\
\hline
\end{tabular}

\section{COMPARISON WITH PREVIOUS WORK}

Figure 14 [15] shows the output voltage versus the time and the maximum overshot almost is zero. The simulation results clearly show that the PID controller gives a much better control of PV system rather than the FOPID controller. When PID tuned by a genetic algorithm is used as a control for the PV system, the rise time was 0.175 second and percentage overshoot was almost zero. In comparison to [3], this work reduced the overshoot with $0.7 \%$ and the rising time by 0.545 seconds.

Also, the neural network has better impact on the PV system rather than PID and FOPID [3] controllers. For Neural Network controller, the overshot was 0.00001 , meanwhile the rise time was 0.170 seconds and Table 4 shows a comparison between all the controller types for PV system. In table 4, the first parameter is the maximum overshoot and the second parameter is the rise time. Figure 15 shows the result of the three different types of the controller that used to enhance the performance of our PV system. The line by the red circles represents the result of PID controller tuned by GA algorithm, the line by the blue crosses represents the results of the neural PSO controller and the line by the black dashes represents the results of a previous work [3]. Figure 16 shows the same result as Figure 15 but with zoomed $x$-axis and $y$-axis.

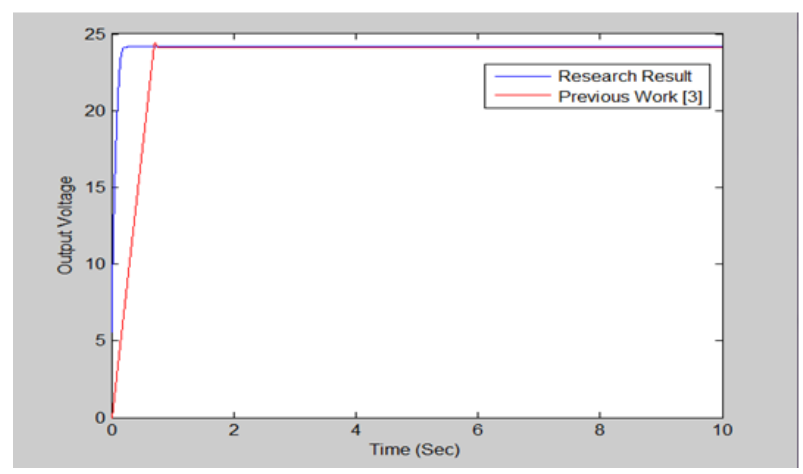

Fig. 14. Output voltage versus time

Step Response of Solar Cell System with different Controller

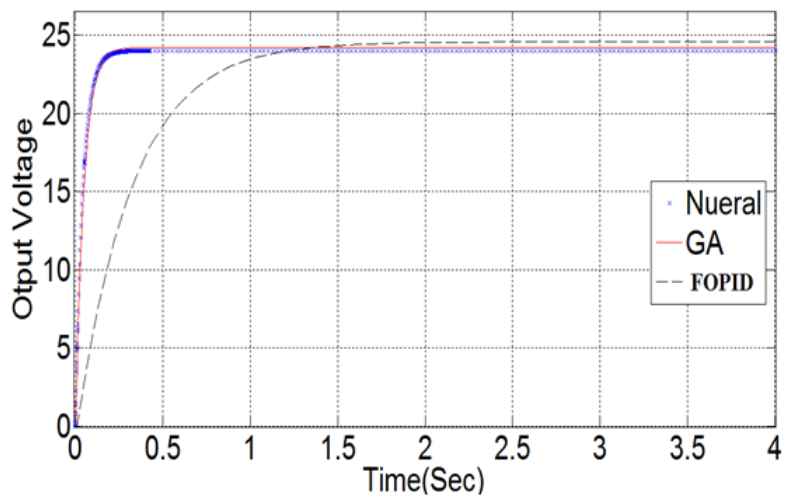

Fig. 15. Output voltage versus time.

Step Response of Solar Cell System with different Controller

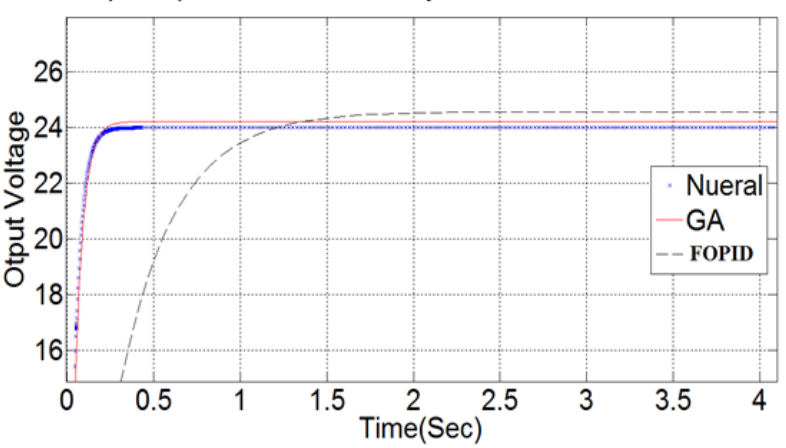

Fig. 16. Output voltage versus time with zoomed $x$-axis and $y$-axis

Table 5. Comparison between this Work and Previous Work $[3,14]$

\begin{tabular}{|c|c|c|c|}
\hline Parameters & $\begin{array}{c}\text { PID with } \\
\text { genetic algoritm }\end{array}$ & {$[3]$} & $\begin{array}{c}\text { Neural } \\
\text { network } \\
\text { controller }\end{array}$ \\
\hline $\mathrm{M}_{\mathrm{p}}$ & 0.1 & 0.8 & 0.00001 \\
\hline $\mathrm{T}_{\mathrm{r}}$ & 0.175 & 0.72 & 0.170 \\
\hline $\mathrm{P}$ & 1.7130 & 19.22 & - \\
\hline $\mathrm{I}$ & 3.8 & 8.32 & - \\
\hline $\mathrm{D}$ & 0.001 & 0.056 & - \\
\hline
\end{tabular}




\section{CONCLUSION AND FUTURE WORK}

$\mathrm{PV}$ system is one of vital renewable energies in the present world. Therefore, researchers made a lot of research on PV panels to enhance its performance. This paper introduces a mathematical model for PV system with neural controller. The neural controller is used to enhance the output of PV system. The PSO is used to optimize the neural controller, which led to minimum overshoot and minimum rise time. The overshoot is reduced to be $0.00001 \%$ and the rise time is set to 0.170 seconds. The results show that neural controller has a better response compared with some other kind of controllers.

For future work, different kinds of controller can be used to control the PV system and different algorithms can be replaced instead of PSO to optimize the neural network controller. The following points may be considered:

- Using different algorithms to tune the Neural Network (NN) controller.

- Using other kinds of controllers to control the PV system and comparing it with the other types used.

- Using a combination of back propagation and neural network hybrid PSO-BP.

- To reach a real time system, the different types of controllers can be implemented on Field Programmable Gate Array (FPGA).

\section{REFERENCES}

[1] N. Pandiarajan and R. Muthu. "Mathematical modeling of photovoltaic module with Simulink," In: Proc. of International Conference on Electrical Energy System, pp. 3-5, 2011.

[2] C. Qi and Z. Ming. "Photovoltaic module Simulink model for a stand-alone PV system." Physics Procedia, vol. 24, pp. 94-100, 2012.

[3] E. Sahin, Erol, M. S. Ayas and I. H. Altas. "A PSO optimized fractional-order PID controller for a PV system with DC-DC boost converter," in Power Electronics and Motion Control Conference and Exposition (PEMC), 2014 16th International. IEEE, pp. 477-481, 2014.
[4] C. A. Monje et al. "Proposals for fractional PI $\lambda D \mu$ tuning," in The First IFAC Symposium on Fractional Differentiation and its Applications, pp. 369-381, 2004.

[5] R. Singhal, S. Padhee and G. Kaur . "Design of fractional order PID controller for speed control of DC motor." International Journal of Scientific and Research Publications, vol. 2.6, pp. 1-8., 2012.

[6] K. Sundaravadivu, B. Arun and K. Saravanan. "Design of fractional order PID controller for liquid level control of spherical tank," in Control System, Computing and Engineering (ICCSCE), 2011 IEEE International Conference on. IEEE, pp. 291-295, 2011.

[7] A. S. K. Chowdhury, K. M. A. Salam and M. A. Razzak. "Modeling of MATLAB-Simulink based photovoltaic module using flyback converter," in Strategic Technology (IFOST), 2014 9th International Forum on. IEEE, pp. 378-381, 2014.

[8] B. Hauke. "Low power DC-DC application/basic calculation of a boost converter's power stage," Texas Instrument application report, pp. 1-9, July, 2010.

[9] L. Y. Chang and H. C. Chen. "Tuning of fractional PID controllers using adaptive genetic algorithm for active magnetic bearing system." WSEAS Transactions on Systems, vol. 8, pp. 226-236, 2009.

[10] A.Biswas, S. Das, A. Abraham and S. Dasgupta. "Design of fractionalorder $\mathrm{P} I \lambda \mathrm{D} \mu$ controllers with an improved differential evolution." Engineering Applications of Artificial Intelligence, vol. 22, pp. 343- 350, 2009.

[11] M. Zamania, M. Karimi-Ghartemanib, N. Sadatib and M. Parnianib. "Design of a fractional order PID controller for an AVR using particle swarm optimization." Control Engineering Practice, vol. 17, pp. 1380-1387, 2009.

[12] J. V. Tu. "Advantages and disadvantages of using artificial neural networks versus logistic regression for predicting medical outcomes." Journal of Clinical Epidemiology, vol. 49, no. 11, pp. 1225-1231, 1996. 
[13] J. Kennedy and R. Eberhart. "Particle swarm optimization," Proc. IEEE International Conference on Neural Networks, vol. 4, pp. 1942 - 1948, 1995. DOI: 10.1109/ICNN. 488968, 1995.

[14] M. Settles. An introduction to particle swarm optimization. Department of Computer Science, University of Idaho, pp. 1-8, 2005.
[15] R. A. AbdelRassoul, Y. Ali and M. Zaghloul. "Genetic Algorithm-Optimized PID controller for better performance of PV system," InternationalConference on Artificial Intelligence (ICCAl'2016), 2016 World Symposium on Computer Applications \& Research, WSCAR 2016, Cairo, Egypt, 12-14 March, 2016, pp. 1822, 2016. 